B 3003

\title{
直交配置された異径2円柱の間隙内に形成する首飾渦の可視化
}

\section{Visualization of Necklace Vortices between Two Cylinders Crossed with Different Diameter}

山田 英巳 ${ }^{\circ}$ (徳山工業高等専門学校)

\author{
Hidemi YAMADA
}

\begin{abstract}
Flow pattern of the necklace vortices in the gap space between two circular cylinders whose diameter is different forming a separated cross was visualized in the symmetrical plane under the Reynolds number of 1500 . The space ratio was altered from $s / d_{1}=0$ to 2.0 , and the diameter ratio was altered from $\mathrm{d}_{2} / \mathrm{d}_{1}=0.67$ to 1.5 . As the results, 8-system of necklace vortices is formed in the wide range of $s / d_{1}$ and $d_{2} / d_{1}$. The space ratio in which the necklace vortex is formed becomes large with the diameter ratio increasing.

Keywords: Necklace vortices, Cross arrangement, Two circular cylinders
\end{abstract}

\section{1. 緒 論}

十字形に直交配置された 2 冈柱間の間隙 $\mathrm{s}$ が比較的小 さい場合、間隙内に首飾渦系が形成されること、そのた め局所抗力係数が激减し、カルマン渦形成が抑制される こと等が明らかにされてきた(1) (3)。一方、直交配置 2 円柱の間陌内に形成される渦の部分的な存在については、 いくつかの研究の中で言及されている(4) が、それら が渦系の一部であることはほとんど認識されていない。 これまでに 2 円柱の間隙の大きさにより首飾渦系が変化 することは報告されている(2)(7)が、Fig.1 のように 2 円 柱の直径が異なる場合までを含めた首飾渦構造に関する 研究はほとんど知られていない。

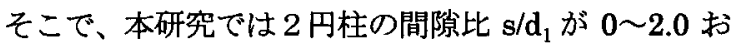
よび直径比 $\mathrm{d}_{2} / \mathrm{d}_{1}$ が $0.67 \sim 1.5$ の範囲に変化した場合つ いて、流れの可視化により下流円柱の軸を通る流れ場の 対称面内で形成される首飾渦の構造を明らかにすること を試みる。
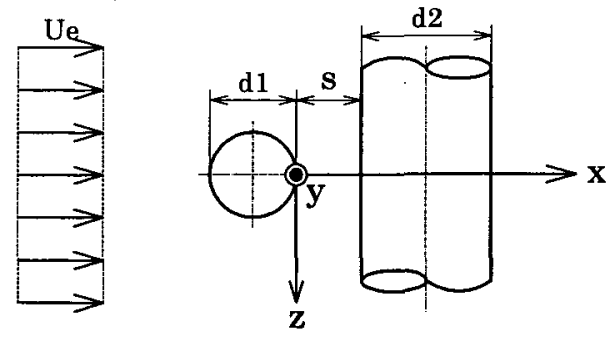

Fig. 1 Coordinate System

\section{2. 実験装置および方法}

実験は、回流式開水路水槽の横断面が $300 \times 300 \mathrm{~mm}$ のアクリル製の測定部内に供試円柱 (直径 $32 \mathrm{~mm}$ と $48 \mathrm{~mm}$ ) を設置して行った。測定部内で上流円柱 $\mathrm{d}_{1}$ を水
平に固定し、移動装置に固定した下流円柱 $d_{2}$ を流れ方 向に自由に移動させ、円柱間隙 $\mathrm{s}$ を変化させた。実験レ イノルズ数は $\mathrm{Re}=\mathrm{Ue} \cdot \mathrm{d}_{1} / v=1000 \sim 1500$ (Ue は主流 速度、vは水の動粘度)とした。間隙内の流れの可視化は、 下流円柱の軸を通り上流円柱の中央 $(\mathrm{y}=0)$ を切断する流 れ場の対称面について、主に流跡線法によって行った。 流跡線パターンの画像は、平均粒径が $0.1 \mathrm{~mm}$ (比重約 1.02）のナイロン微粒子をあらかじめ水槽中に混入させ

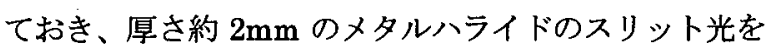
照射してシャッタースピード $1 / 2$ 秒でディジタルカメラ $(2048 \times 1536$ 画素)により撮影して得られた。

\section{3. 実験結果および考察}

\section{1 同径 2 円柱の場合}

Fig.2(a) (d)は、間隙比が $\mathrm{s} / \mathrm{d}=0.1 \sim 1.0$ の場合の $\mathrm{y}=0$ 対称面における流跡線パターンを示寸。 $\mathrm{s} / \mathrm{d}=0.1$ の場合、 上流円柱の片方の曲壁面上で剥離した直後の流れが 1つ の渦Aを形成していることが分かる。さらにこの渦を取 り囲むように近づいた流れが下流円柱の前方で急激に曲 げられ、 $\mathrm{z}=0$ 位置の近傍の上方で反時計回りの小さい瀜

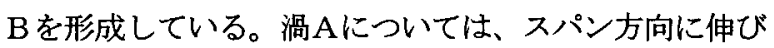
て上流円柱背面の $\mathrm{y} / \mathrm{d}= \pm$ 約 1.5 の位置から流出する比 較的大きいスケールの随伴渦に巻き込まれている可能性 が高いと思われる(た。一方、渦Bについては、その存在 が隙間比の小さい場合には不明瞭であったが、可視化結 果は明確にその存在を示していた。このような下流円柱 表面を取り囲んで流下寸る渦 $\mathrm{B}$ の流丹柱背後における 挙動は今のところ不明である。

間隙比が $\mathrm{s} / \mathrm{d}=0.2$ になると、上述の時計回りの渦 $\mathrm{A}$ は 2 つの時計回りの渦とその中間位置での反時計回りの渦 へと分岥する。少なくとも、このうちの最下流位置にあ 
る最大スケールをもつ時計回りの渦 (主渦)が首飾渦とし て下流円柱を取り囲むようにして流下寸る(3)(6)(8)。残り 2 つの渦と渦 B の生成後の挙動は不明である。以上の結 果より、上流円柱の片側面に 4 個の渦が存在するので、 全体として 8 個の渦が形成されている。Fig.2 のように この 8 渦系の首飾渦構造は間隙比が $\mathrm{s} / \mathrm{d}=1.0$ まで観察さ れるが、 $\mathrm{s} / \mathrm{d}=0.8$ 以上になると主渦の大きさが急速に拡 大して摇れ始める。この首飾渦系 (渦数)の変化を Fig.3 に示寸。渦パターンは $\mathrm{s} / \mathrm{d}=1.5$ になるとカルマン渦のよ うに交互に上流円柱から離脱するのが観察された。

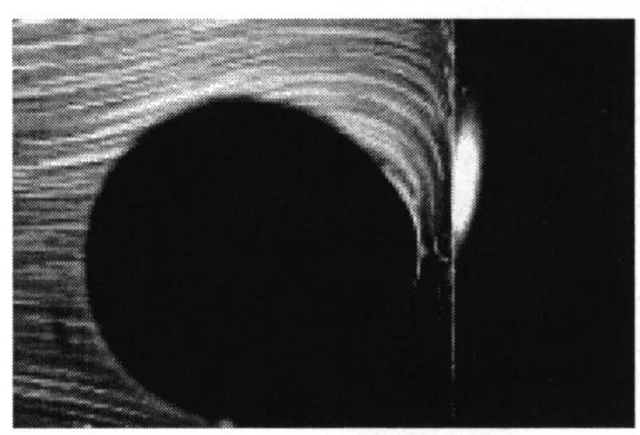

(a) $\mathrm{s} / \mathrm{d}_{1}=0.1$

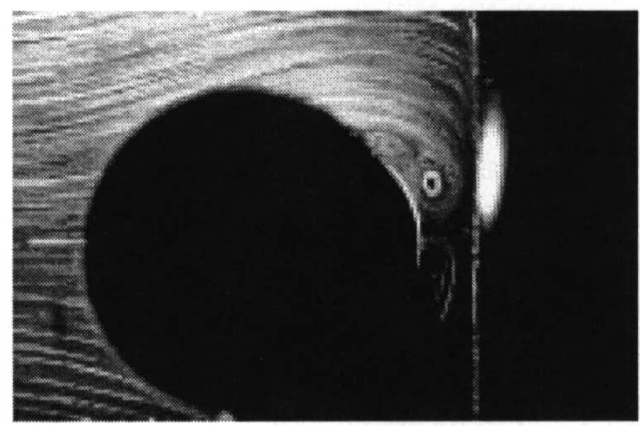

(b) $\mathrm{s} / \mathrm{d}_{1}=0.2$

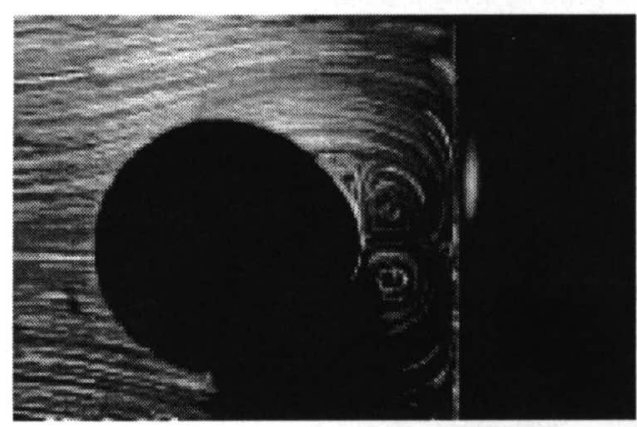

(c) $\mathrm{s} / \mathrm{d}_{1}=0.5$

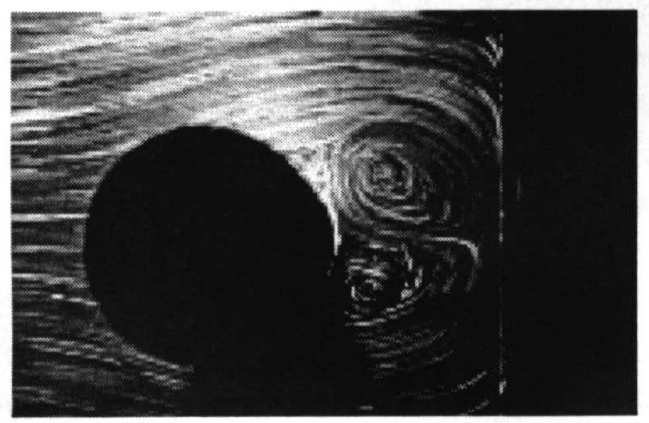

(d) $\mathrm{s} / \mathrm{d}_{1}=1.0$

Fig.2 Flow Pattern in the Case of $d_{2} / d_{1}=1.0$

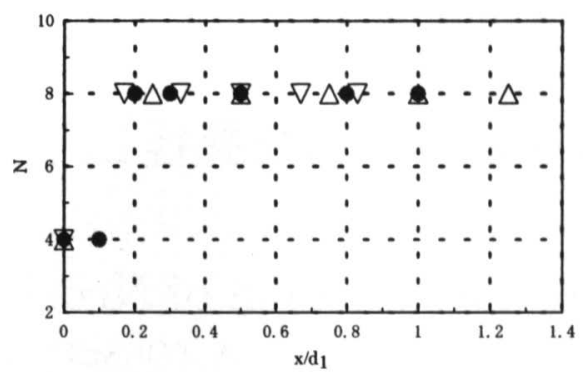

Fig.3 Necklace Vortex System

\section{2 異径 2 円柱の場合}

Fig.4(a),(b)は、間隙比 $\mathrm{s} / \mathrm{d}_{1}=0.5$ で直径比 $\mathrm{d}_{2} / \mathrm{d}_{1}=1.5$ お よび 0.67 の場合を示す。 2 円柱直径が等しい場合に比 ベ、Fig.4(a)の下流円柱が大きい場合には間隙部で主渦 が上下に大きく摇動し、Fig.4(b)の下流円柱が小さい場 合には大きな摇動は見られないものの渦パターンが不明 瞭になっている。さらに間隙比が大きくなると対になっ ている主渦が上流円柱の背面から交互に離脱するように なる。このように主渦が明瞭に交互に離脱するものを力 ルマン渦とすると、首飾渦が形成される間隙比の範囲は、 Fig.3 からも分かるように直径比が $\mathrm{d}_{2} / \mathrm{d}_{1}=0.67$ ( $\triangle$ 印) 、 1.0 (○印)および 1.5 ( $\nabla$ 印) の場合におよそそれぞれ $\mathrm{s} / \mathrm{d}_{1}=0.83 、 1.0$ および 1.25 であった。

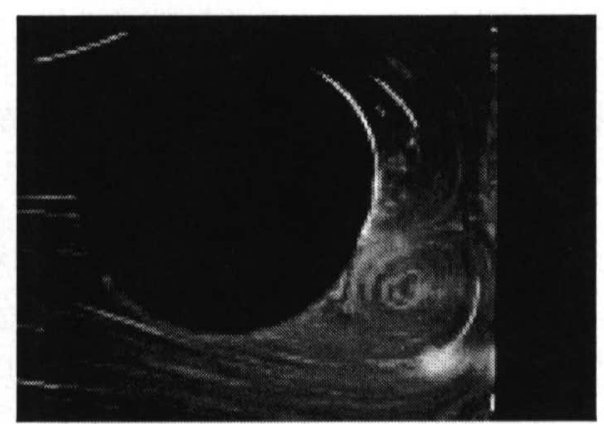

(a) $d_{2} / d_{1}=1.5$

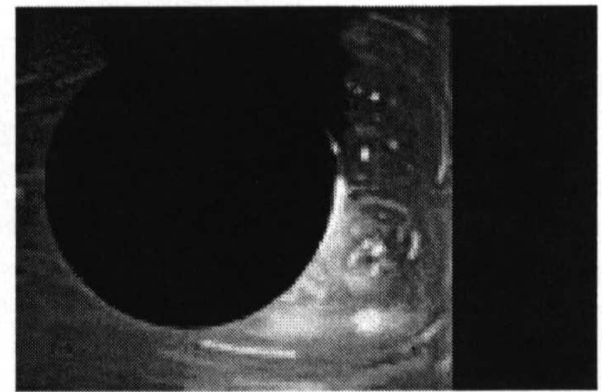

(b) $\mathrm{d}_{2} / \mathrm{d}_{1}=\mathbf{0 . 6 7}$

Fig.4 Flow Pattern in the Case of $\mathrm{s} / \mathrm{d}_{1}=\mathbf{0 . 5}$

参 考 文 献

1) 山田 : 可視化情報, Vol.19, Suppl. No.2 (1999), 47-48.

2) 山田ら : 機講論, No.845-1 (1984), 85-87.

3) 山田ら : 機講論, No.898-3 (1989), 107-108.

4) 馬淵ら : 機論 B, 55-516 (1989), 2441-2449.

5) Fox,T.A. : J. Fluids Eng., ASME, Vol.113 (1991), 45-50

6) Bae,H.M. 白樫 5 : 機論 B, 58-551 (1992), 2093-2099.

7) 山田ら : 機講論, No.038-2 (2003), 111-112. 